\title{
PONTUAÇÕES ACERCA DO AMOR NA NEUROSE E NA PSICOSE: ENSINAMENTOS DE CAMILLE CLAUDEL
}

NOTES ABOUT LOVE IN NEUROSIS AND PSYCHOSIS: TEACHINGS FROM CAMILLE CLAUDEL PUNTUACIONES ACERCA DEL AMOR EN LA NEUROSIS Y EN LA PSICOSIS: ENSEÑANZAS DE CAMILLE CLAUDEL

\author{
Ilka Franco Ferrari* \\ Astarute Maria Mendes
}

\begin{abstract}
RESUMO
O texto percorre o tema de parcerias amorosas, com base em ensinamentos da psicanálise freudiana e lacaniana, sem desconsiderar, portanto, que não há norma para a relação sexual e que, se há gozo autoerótico, o amor lhe faz oposição ao favorecer abertura para o Outro. Nesse percurso, elegeuse tecer considerações baseadas em certos modos de funcionamento de parcerias amorosas, na neurose e psicose. O foco na psicose é um pouco mais ampliado, na busca de afirmar que esses sujeitos têm a possibilidade de amor, diferentemente do que se pode pensar. Por isso, Camille Claudel é convocada à cena, na busca de ensinamentos sobre o amor morto, discordante com a vida, característico da psicose, vivenciado na parceria com August Rodin.
\end{abstract}

Palavras-chave: Amor. Psicanálise. Neurose. Psicose. Camille Claudel.

\begin{abstract}
This text approaches the theme of love partnerships based on Freudian and Lacanian psychoanalysis, without disregarding, therefore, that there is no norm for sexual intercourse and that if there is autoerotic pleasure, love acts against it by favoring an open access for the Other. It was decided to weave considerations from certain modes of functioning of love partnerships in neurosis and psychosis. The focus on psychosis is some way more amplified, with the purpose of stating that these subjects have the possibility of love, opposing to whatever one may think. Therefore, Camille Claudel is summoned to the scene, in search of teachings on what is called by Lacan as "dead love", in disagreement with life, characteristic of the psychosis, experienced in the partnership of Camille with August Rodin.
\end{abstract}

Keywords: Love. Psychoanalysis. Neurosis. Psychosis. Camille Claudel.

\footnotetext{
Texto recebido em 10 de julho de 2017 e aprovado para publicação em 23 de fevereiro de 2018.

*Professora dos cursos de Graduação e Pós-Graduação em Psicologia da Pontifícia Universidade Católica de Minas Gerais (PUC Minas), membro da Escola Brasileira de Psicanálise - Seção Minas Gerais e da Associação Mundial de Psicanálise (Paris). E-mail: francoferrari@terra.com.br.

** Mestra em Intervenções Clínicas e Sociais pela PUC Minas, especialista em Clínica Psicanalítica, psicóloga clínica. E-mail: astamendes@uol.com.br.
} 


\begin{abstract}
RESUMEN
El texto recorre el tema de las relaciones amorosas desde enseñanzas del psicoanálisis freudiano y lacaniano, considerando, por lo tanto, que no hay norma para la relación sexual y que, si hay goce autoerótico, el amor se opone al favorecer la apertura al Otro. En este recorrido, se escogió tejer consideraciones desde ciertos modos de funcionamiento de relaciones amorosas en la neurosis y en la psicosis. El enfoque en la psicosis es algo más expandido, en la búsqueda por afirmar que estos sujetos tienen la posibilidad de amor, diferentemente de lo que se puede pensar. Por ello, Camille Claudel es convocada a la escena, en la búsqueda por enseñanzas sobre el amor muerto, discordante con la vida, característica de la psicosis, vivido en la relación con August Rodin.
\end{abstract}

Palabras clave: Amor. Psicoanálisis. Neurosis. Psicosis. Camille Claudel.

\title{
1. INTRODUÇÃO
}

O tema do amor é caro à psicanálise, que se interessou por ele de diferentes modos, a exemplo de pensá-lo na transferência, nas parcerias amorosas, nos conflitos em que se constatam sintomas intrassubjetivos e intersubjetivos, como assinala Miller (2003, p. 16). E, quando os estudiosos se interessam pelas estruturas subjetivas, nelas encontram neuróticos e psicóticos ensinando acerca de suas formas peculiares de amar.

\section{AMO EM TI MAIS DO QUE TU}

No cotidiano da vida, os neuróticos nos defrontam com o jogo de érastes, ou seja, de um sujeito que ama e presume-se faltoso, não localizando o que lhe falta, e de éroménos, o amado, alguém que também não está ciente do que lhe faz ser atraente aos olhos do amante. Assim, como afirma Lacan (1960/2010, p. 56) ${ }^{1}$, "O que falta a um não é o que existe, escondido no outro. Aí está todo o problema do amor. [. . .]. No fenômeno, encontra-se a cada passo o dilaceramento, a discordância”.

Por esses meandros, ao escrever acerca do amor de Alcibíades por Sócrates, Lacan (1960) percorreu caminho que leva seu leitor ao que sintetiza pouco depois, ou seja: no "eu te amo", há, inexplicavelmente, algo que amo em ti mais do que tu, referindo-se ao o objeto $a$ minúsculo. E, por isso mesmo, ao te amar, "eu te mutilo" (Lacan, 1964/2008, p. 260).

\footnotetext{
1 A primeira data indica o ano de publicação da obra, e a segunda, a edição consultada pelo autor, a qual somente será pontuada na primeira citação da obra no texto. Nas seguintes, será registrada apenas a data de publicação original.
} 
Aqui já se pode ler que o neurótico sofre por amar ao próximo como a si mesmo, ou por querer ser amado como ama a si próprio. Mas o entendimento dessas ponderaçôes lacanianas pode também ser favorecido por Miller (2003), no livro La pareja y el amor. Ali, a partir dos casos apresentados e comentados, o autor estabeleceu alguns modelos de parcerias amorosas, constituídos a partir da teoria analítica, advertindo que o faz sem intenção de exaustividade, pois não há uma norma para a relação sexual. Circunscreveu aqueles em que há eleição de objeto narcisista, sustentada na versão do eu ideal, no como se gostaria de ser, ou pela via da identificação a um dos pais. Outros se situam no modelo fantasístico, com o parceiro parecendo responder à fantasia do sujeito, em parceria na qual certa complementariedade pode ser assegurada, em geral constituindo vínculos fortes, ainda que em meio a problemas. Há, ainda, a eleição sintomática, que supõe a vertente fantasística, mas aqui a diferença está no fato de que o parceiro não está fora do sujeito, embora seja distinto do seu eu, pois é equivalente a um sintoma. E, nesse ponto, ele chega ao que passou a formalizar como parceirosintoma, parceria especial, na qual o que há é um semblante de parceiro, o parceiro é um semblante, já que o real do parceiro é um sintoma do sujeito. Nessa parceria nota-se a dimensão do gozo autoerótico fechado em si, solitário, e a do amor, que faz com que o sujeito se abra para o Outro. Aqui está, portanto, o amor fazendo oposição ao gozo autoerótico, promovendo abertura para o Outro e retirando o parceiro da pura condição de sintoma.

Miller (2000, p. 156), em outra ocasião, já havia frisado, em modo lacaniano de pensar, que o amor quer dizer que a relação com o Outro não é estabelecida por qualquer instinto, já que mediada pelo sintoma: "Eis porque Lacan pôde definir o amor como encontro, no parceiro, dos sintomas, dos afetos, de tudo o que nele e em cada um marca o rastro de seu exílio da relação sexual". Dessa forma, o parceiro fundamental do sujeito é algo que lhe é próprio, isso implicando seu sintoma, sua imagem derivada do estádio do espelho, seus objetos, objeto a revelado a partir da estrutura da fantasia, extraído do corpo, mais de gozar fundamentando a parceria entre sujeito e Outro. Isso implica, consequentemente, que a escolha de um parceiro sexual está baseada em como este se adequa ao modo próprio de gozar de cada qual. No encontro com o Outro joga-se, portanto, não com ele/Outro, mas com o gozo próprio. Funcionamento gozoso, modo de dizer do sintoma, e, assim, resulta fácil deduzir que a sustentação de uma parceria amorosa se deve aos sintomas.

Assim, ainda que estruturalmente o amor seja recíproco, ele sempre tem uma face de clara impotência! Ele não consegue realizar o desejo de fazer Um a partir de dois; não consegue estabelecer a relação sexual (Lacan, 1972-1973/2008), já 
que não há complementariedade entre os sexos, em decorrência da discordância fálica existente entre eles.

Ensinamentos dessa ordem já podem ser vistos nas formalizações freudianas, e muito especificamente no que chamou de "Contribuiçôes à psicologia do amor", dos anos 1910, 1912 e 1917, apresentadas à Sociedade Psicanalítica de Viena. Nelas, pode-se constatar como mecanismos inconscientes condicionam escolhas de objetos amorosos, e como o princípio do prazer sofre inquietação tão logo o desejo apresenta-se, fazendo com que a pretensa homeostase, reguladora de tensões, desapareça.

Vale a pena, neste momento, trazer para a cena um psicanalista da atualidade, Ebtinger (2006, p. 55), conhecedor da obra de Freud e de Lacan. Ele enfatiza o fato de os amores neuróticos responderem "às necessidades do inconsciente", e considera que podem ser reconhecidos em duas formas de manifestações: no prazer e na falta. Eles se deixam notar no prazer presente nos pensamentos referentes ao objeto de amor, mas o pensamento "está bordeado em maior ou menor medida pela falta, que é outro signo do amor" (Ebtinger, 2006, p. 55).

Essa falta corresponde ao fato de que, para circunscrever a experiência de amor, não há palavras suficientes, ainda que cantadas em verso e prosa, nem sexo nem gozo corporal. E, quando estudiosos nela se detêm, em geral se deparam com o fato de que ela pode ser considerada causa do amor que busca complementariedade, reunião, fusão, encontro ideal. Consequentemente, o que se constata clinicamente é que nesse ponto onde o amor passa a ser resposta para a falta, ponto imaginário, o fracasso amoroso aparece e, no contexto, "Já não se pode pretender mais que a beleza de uma natureza morta. Assim são os amores daqueles que perderam as pegadas do desejo, quando sobrevivem ao extravio do desejo", como diz sabiamente Ebtinger (2006, p. 56).

Por outro lado, estudiosos também se deparam com a possibilidade de a falta surgir como consequência do amor que a revela, faz existir. Pode-se deduzir que o encontro amoroso é o da encarnação dessa falta, da qual emana sua vida e faz o amor vibrar. Aqui está, portanto, nas palavras do autor mencionado, o amor situado do lado da vida, aquele amor que não se deixa trair na preocupação de preencher a falta. Nessa posição, ele pode sobreviver, no reconhecimento de que, quando se ama o objeto, coloca-se de forma manifesta minha falta e o que ela põe em jogo. E assim são os amores que procedem do desejo e do real, não mais situados no plano da dinâmica metafórica, na qual aquele que ocupa o "lugar de [. . . ]" tenta em vão preencher a falta, dimensão imaginária. A falta que supõe o amor vivo conta com a metonímia, com abertura para o novo, com a palavra do amado ou da amada, distinta das palavras de puro reconhecimento, a exemplo 
de "você é meu marido", "minha esposa", "meu amor"[. . .] São palavras que testemunham que cada qual caminha por si, mas submete seu passo ao outro, em alguns casos até dedicando-se a isso. Situação que pode ser lida em Figueiredo e Muñoz (2015, p. 144), quando dizem que "Na neurose, uma vez que o sujeito assume, por meio da inscrição do Nome do Pai, a existência de uma lei simbólica vinda do Outro, o amor pode se apresentar em sua dimensão simbólica de pacto, freando o desarranjo imaginário".

A dimensão do sexo faz ressoar essa falta que se origina no real, não reabsorvida nas representaçóes, e muito menos nas formas de gozo, e que o plano imaginário tenta velar. $\mathrm{O}$ tema que envolve sexo e amor traz questóes que os psicanalistas conhecem bem, desde Freud. Aqui é bom acompanhar a clareza com que Ebtinger (2006) trata o assunto. Ele recorda a seus leitores que o sexo traz emoção para as parcerias amorosas ou as destrói. Quando promove o êxtase, por exemplo, escancara a solidão de cada sujeito, a solidão do gozo e a impossibilidade de remediar a falta do outro. E, daí, evidencia o desacordo próprio de toda relação de parceria, na evidência de que há gozo que se separa do Outro. Assim, a satisfação sexual não faz união, mais que nada, supõe desapego, separação e é a falta de um encontro que consuma o ato sexual, momento em que "todos fecham os olhos".

Sem dúvida, trata-se de autor bem lacaniano, e que conhece o Seminário "mais, ainda [...]", no qual está escrito que "O gozo do Outro, do Outro com A maiúsculo, do corpo do Outro que o simboliza, não é signo de amor" (Lacan, 1972-1973, p. 12) e que, ainda que no amor trate-se de paixão que ignora o desejo, nem por isso é capaz de privá-lo de seu alcance. Nessa direção, Ebtinger (2006, p. 58) assevera que a afirmação lacaniana favorece a leitura de que pode não haver a ignorância do desejo no amor e, consequentemente, este pode encontrar caminho mais atrevido, ajustado a uma "falta positiva, produzida e respaldada em suas consequências, tanto na palavra como no corpo", colocando em jogo uma falta que exige consentimento do sujeito. Dessa forma, "Se o amor é algo diferente de uma captura imaginária, ele deve ser pensado com o desejo" (Ebtinger, 2006, p. 58), em entrelaçamento que supõe o objeto de amor na significação fálica, a falta no Outro e o valor do objeto $a$.

Não sem razão, como se nota, Lacan (1960, p. 49) dizia que "amar é dar o que não se tem”, pois o que se ama, no amor, não é o sujeito, mas o que ele não tem, ou seja, o amor se encontra "não no objeto, mas naquilo que o objeto não tem" (Lacan, 1957/1988, p. 131). Aí se centram as possibilidades de dizer da mediação sintomática no amor. E por esses meandros, nos quais os neuróticos ensinam e deixam ler que a relação sexual não existe, faz-se o caminho para refletir sobre as parcerias na psicose. 


\section{PSICOSE: QUEBRA NO TOCANTE AO CUMPRIMENTO DO QUE SE CHAMA AMOR}

Um leitor cuidadoso, que percorre a obra freudiana, não tem como evitar a pergunta sobre a possibilidade do amor na psicose, a não ser que centre seu foco no que Freud escreve sobre o narcisismo presente no amor. Até certo ponto, isso também acontece na psicanálise lacaniana, até que nela não se despreze alguns textos fundamentais.

Ao trabalhar o sucedido com Aimée, para pensar a transferência em época que se preocupava com o que se passa com o amor na psicose, Lacan (1932/2011) escreveu que a aspiração amorosa está fadada ao fracasso, quando discordante com a vida. Passados anos, em uma de suas conferências norte-americanas (Lacan, 1976, p. 16), na Yale University, Kanser Seminar, nesta direção, ele afirmou que "a psicose é uma espécie de quebra no tocante ao cumprimento do que se chama amor", o que se esclareceu no Seminário 3 (Lacan, 1955/1988), quando apareceu sua formalização sobre o amor morto, discordante com a vida.

$\mathrm{Na}$ perspectiva lacaniana, considerar a questão do amor, na psicose, supõe focar na relação descentrada com o Outro, radicalmente estranho, que eles vivenciam, em nada favorecedora da reciprocidade que é própria, inerente à condição amorosa. Nesse ponto, não se pode ignorar a existência de relação amorosa com o Outro como radicalmente Outro, com a situação em espelho, na ordem imaginária. E, por isso, de forma bem didática, em determinado momento do Seminário 3, ele se pergunta a que se deve a diferença entre alguém que é psicótico e alguém que não o é, cuidando para responder objetivamente. Responde asseverando que, "para o psicótico, uma relação amorosa é possível abolindo-o como sujeito, enquanto ela admite uma heterogeneidade radical do Outro. Mas esse amor é também um amor morto" (Lacan, 1955, p. 296). Amor morto, pois aqui o sujeito será objeto real de gozo para esse sujeito do amor que para ele é tão diferente, tão consistente, e por ele vai se sacrificar. Nas palavras de Muñoz (2010, p. 2), esse amor "é aquele que pode exibir a morte do sujeito em seu horizonte".

Torna-se desnecessário afirmar, mas é bom lembrar, que Lacan era conhecedor dos ensinamentos freudianos, para quem o amor não parte do Outro, mas do narcisismo, e garantiu o narcisismo na origem da psicose, plano imaginário, até a colocando, por um tempo, dentro da classificação de neuroses narcísicas, diferentemente das neuroses de transferência. Nessa direção, Lacan (1955, p. 244) considerou que o psicótico, por não conseguir ou perder o Outro, encontra o outro puramente imaginário, "diminuído e decaído, com o qual não pode ter outras relações que não as de frustação". Tal como escreve Muñoz (2010, 
p. 3), de forma bem lacaniana, uma vez que o sujeito, na paixão, não se coloca no lugar de ativo, ele será passivo e receberá do Outro traiçōes, perseguiçõoes, manifestações de ódio: "As virtualidades mortíferas do amor se concretizam, então, em três riscos: a destruição da paixão, do sujeito ou de seu objeto". Isso porque, na falta de certa regulação prévia, relacionar-se com um parceiro pode estar na base de desencadeamento ou desestabilização, vivenciando o amor não como agente, mas como vítima dele. Não há muita margem para a entrada de um terceiro ou de qualquer elemento que se coloque na dualidade estabelecida pelo sujeito e o outro.

O usual, portanto, é a promoção de devastação, de estragos, e fato inquestionável é que a reciprocidade, exigida pelo amor, nesses casos, constitui tarefa difícil, melhor dizer impossível, pois não há como ser recíproco a alguém tão desproporcional como é o outro para o psicótico.

Ebtinger (2006), autor de nossa realidade social, por sua vez, não desmente tais constataçôes e adverte, de forma bem precisa, que, na psicose, em sua ausência da significação fálica, dificuldades com a simbolização e localização do gozo, se não é improvável a existência do objeto de amor, ela, no mínimo, é problemática. Esses sujeitos ensinam que o amor pode ter sua vertente de rechaço do ser, repulsa do desejo, afastamento do sexo. Se eles não podem se representar pela imagem fálica, o órgão não passa pela mutação fálica, daí o gozo deixa de ser localizado e o enlaçamento entre vida e morte, que a detumescência mostra, faz-se impossível, trazendo a questão de como se sustentar na ereção de ser vivo. O amor, situado do lado da vida, como já se escreveu, é o que supõe a falta que lhe vivifica e o faz vibrar, o que não existe na psicose, em função do que sinteticamente Ebtinger pontuou e Lacan já havia dito em seus textos iniciais. Para esses sujeitos, desamparados do simbólico, na ausência da castração, a consequência é a "não extração do gozo ou do objeto" e, portanto, falta-lhes "a disjunção entre o lugar do Outro e o gozo", a permissão para que se instaure a dimensão da falta" (Ferrari, 2009, p. 6). A esses sujeitos, assim sendo, não faz falta o amor como resposta à inexistência da relação sexual. Para eles, a relação sexual faz-se possível, dado que o outro não é faltoso, como bem ensina Schreber.

Sabe-se, no entanto, de raridades em que a possibilidade do amor estabiliza o sujeito, ao promover identificação imaginária. Ferrari (2009, p. 7) frisa: "No que tange à reciprocidade que o amor supõe, se o psicótico não está em condições de oferecer algo dessa ordem, isso não significa que ele nada tenha a ofertar. Há, por exemplo, vínculos da ordem da amizade que lhe seria possível constituir", a exemplo de Schreber e Joyce. Suas mulheres não se constituíam em objeto causa de desejo, mas se prestavam a lhes servir. Havia certa parceria, uma amizade, 
ou uma relação institucionalizada, com regras e com o consentimento dessas esposas, uma vez que elas, a partir de seus sintomas, estavam implicadas nesse enlace.

Lacan chamou atenção dos interessados que Schreber foi capaz de manter seu amor pela esposa, mas na forma de amizade elevada, no sentido do que Aristóteles (2005), em Ética a Nicômaco, denominou philia, ou seja, um amor privado do gozo sexual, tal como aqueles expressos em gestos ou práticas de ações benéficas, nos laços entre moradores de um mesmo local buscando o bemestar do outro, amizade cívica em que os cuidados necessários e as regras são cumpridas, prescindindo de real afeição. $\mathrm{Na}$ ausência da significação fálica, o sujeito não pode identificar-se com o tipo ideal de seu sexo, e muito menos responder, sem graves consequências e riscos, às necessidades de seu parceiro na relação sexual. Nessa ausência, o que se manifesta é o estatuto real do sujeito como objeto, até mesmo dejeto, indefeso frente ao gozo infinito do outro, pronto para ser mortificado. Muñoz (2010), por exemplo, menciona que uma das saídas possíveis para estabilização na psicose está relacionada à resignação ao sexual e, assim, o platonismo faria uma borda ao gozo desregrado que a caracteriza. A clínica ensina que, de fato, existem muitos psicóticos afirmando a renúncia ao sexual, com isso se estabilizando, mas outros nem chegam a cogitá-lo.

Outra questão que merece ser mencionada éo amor do psicótico por seu delírio, sua capacidade de amá-lo, já observada por Freud. Miller (2006), por exemplo, diante das afirmaçôes lacanianas de amor morto na psicose, questionou se esse caráter mortífero diz respeito ao sujeito amar um ideal e substituir a realidade do parceiro por um outro tão heterogêneo, tão impossível de ser encarnado por um vivente a não ser em seu delírio, ou se diz respeito ao sujeito amar somente a si mesmo, ou, ainda, se isso deve-se ao fato de, como disse Freud, o psicótico amar seu delírio mais do que tudo.

E, nesse momento, é bom trazer ao leitor a consideração de Miller (2006), quando ele diz que o amor, nas psicoses, ensina sobre o amor de uma forma geral, pois suas características exacerbadas aplicam-se ao amor como tal. Amar é, antes de tudo, querer ser amado. A subjetividade de um é sacrificada em privilégio do outro, a fim de se fazer objeto do outro no amor. A realidade do sujeito pode dissipar-se, e até desaparecer, no amor. 


\section{ENSINAMENTOS DE CAMILLE CLAUDEL}

No mundo acadêmico em que a psicanálise se faz presente, Camille Claudel é exemplo paradigmático de paranoia, até mesmo porque seu diagnóstico se deu com ela ainda viva. Ela nasceu em 8 de dezembro de 1864, em Villeneuve, arredores de Paris, após sua mãe haver perdido um bebê, menino, com quinze dias. Nas palavras de Rocha (2001), diante do nascimento de uma menina, ainda que saudável, essa mãe virou o rosto e não pronunciou uma palavra sequer, por horas. Após seu nascimento, os pais tiveram dois outros filhos, Paul e Loise. A relação com a mãe, que a via como estranha e preferia sua filha menor, Loise, que chegou após a vinda de um filho homem, não era fácil: "Muito desprezo e indiferença era o tom desse relacionamento materno frágil e distante [. . .] uma mãe fechada, pesada, espessa” (Rocha, 2001, p. 15).

Nas palavras de Wahba (2002), a relação da mãe de Camille com os filhos era permeada de reservas, controle, ausência de demonstração de afeto, ou seja, de dificuldades para favorecer a localização do sujeito no desejo do Outro. Encontrar um lugar no desejo da mãe é crucial para que a criança possa constituir-se como sujeito desejante e, assim, encontrar subsídios para responder sobre seu próprio ser. Para Drummond (2011), Camille Claudel ilustra muito bem uma mulher que, embora encontrasse, por parte do pai, incentivos para seu talento artístico (pai que se comportava com ela de modo afetuoso), era extremamente hostilizada pela mãe, que inclusive a nomeava de usurpadora da família, termo que futuramente Camille repete em relação a Rodin, alegando que ele usurpava de seu talento. Pai afetuoso, mas com dificuldades de intervir diante dos excessos maternos e de cumprir a função de regular a falta de libidinização da criança por parte da mãe.

$\mathrm{Na}$ adolescência, a beleza de Camille aflorou: olhos azuis, boca enorme, longos cabelos castanhos, inegavelmente atraente. Nas palavras de Rocha (2001), ela amava as madrugadas, a vida fora das horas da família, sempre pronta e à espreita de uma fuga, em lei desconhecida, como é possível considerar, e, pelos incentivos de seu mestre da época, Alfred Boucher, a família foi viver em Paris, em 1877, época em que conheceu Rodin, que até então somente havia ouvido falar sobre estilo semelhante ao seu. Em sua imaginação, ele não passaria de um velho com o qual não simpatizava, sem ter tido contato, e nessa época Rodin não tinha fama e, por vezes, era criticado pelos academicistas, em razão de sua forma incomum de esculpir.

Ao conhecer Camille, Rodin encantou-se por sua beleza e talento, e ela passou a se atrair por ele, que lhe assinalava ser famosa e, identificada a essa posição, posicionou-se oferecendo-se como objeto de gozo, próprio de sua 
constituição psicótica. Ela lhe servia como modelo, consultava-o acerca do que fazia, estimulava-o a produzir, frequentar salóes, em tudo configurando a forma de amor morto, proposta por Lacan, no apagamento do sujeito. Ele não se cansava de desenhá-la e, diferentemente dos anos até 1881, em que sua obra não mostrava a sensualidade feminina, realizou obras como "O beijo", "A eterna primavera", "O eterno ídolo", "As sereias", e "A Danaide". Foi aclamado e comparado a nomes como Michelangelo, mas Camille mantinha-se afirmando seu estilo, embora cada vez menos produzindo, já que, segundo Wahba (2002), as esculturas de Camille e Rodin eram permeadas de diálogos amorosos. Nessa época, ela já havia deixado a casa dos pais e se mudado para um ateliê que Rodin havia comprado para que pudessem trabalhar juntos e viverem seus momentos de amor, estando Camille na condição de sua amante, já que ele ainda vivia com sua esposa, Rose.

Havia um triângulo amoroso explícito, que contava com a falta de mediação fálica: Rodin, em parceria que tudo sugere ser estruturada em lógica neurótica, não conseguia se separar de sua esposa, na alegação de que ela sofreria e não resistiria. Era grato a ela, que o havia amparado em seu luto pela perda de sua irmã, além de temer um possível escândalo que o levaria ao declínio do prestígio como escultor. Na lógica de funcionamento com Camille, no circuito supondo a psicose, segundo Rocha (2001, p. 23), "Camille iluminava Rodin, mas não a si mesma [. . .]. Esta era a grande verdade inconsciente de Camille: era operária de Rodin, sua modelo, sua inspiração e companheira”.

Diante da angústia que a vida lhe apresentava, e farta de tudo, dependente, insegura e solitária, Camille afastou-se gradualmente de Rodin diante da constatação de que ele não atenderia a seu pedido de separar-se de Rose. Daí, em 1892, surgiram os trabalhos intitulados "A convalescente", "O adeus" e "Orfeu e Eurídice”, simbolizando o rompimento da relação com Camille. Ela havia vivido isolada no ateliê e até conseguiu disfarçar uma gravidez que terminou em um aborto, que não se sabe se ocorreu de forma espontânea ou forçada. Sentia-se "abandonada à própria sorte, sem projetos, sem exigências, uma verdadeira velha aos vinte e cinco anos" (Rocha, 2001, p. 25), em meio a brigas, violência, ameaças, que a faziam se isolar ainda mais. Ela chegou a esculpir uma peça na qual se pode ler a triangularidade vivida: nela, há um homem ao centro, envolvido por uma mulher mais velha, sugerindo Rose, e uma mulher mais jovem, Camille.

O rompimento definitivo entre Camille e Rodin deu-se no ano de 1898, a partir do qual ela tentou refazer sua vida e manter-se como escultora, até recebendo o título de membro da Sociedade Nacional de Belas Artes. Algumas de suas esculturas dessa época foram intituladas como "O deus que voou", 
"A implorante", "A idade madura", "As faladeiras". Mas os prêmios dandolhe notoriedade não a convenciam, ainda que contasse com apoio dos críticos ponderando sua condição de mulher. Ela chegou a esculpir uma imagem de mulher ajoelhada, por alguns considerada como que implorando por algo. Em psicanálise, pode-se pensar na expressão do estatuto real do sujeito como objeto, dejeto, indefeso frente ao gozo infinito do outro, mortificada, em realidade na qual falha a operação simbólica. Sabe-se que ela suplicou a Rodin para que não a deixasse, e que este significante, "implorante", a acompanhou até o fim da vida, estando presente nas cartas enviadas à família e aos médicos para que pudesse sair do asilo de Montdevergues.

Sua arte não conseguiu amarração suficiente entre os registros real, simbólico e imaginário, a construir um sinthoma que pudesse lhe valer como suplência e impedisse o desencadeamento de sua psicose, que ocorreu ao perder seu amado. Pode-se presumir que a relação amorosa com Rodin a manteve estabilizada por um tempo, pois, enquanto trabalhavam juntos, mesmo que em triângulo amoroso, ela parecia ter um lugar, era admirada, útil a Rodin, sua musa, e acreditava que ele deixaria a esposa para viver com ela. Com o rompimento, quebrou-se a identificação imaginária que a mantinha articulada a uma imagem, apoiada, daí não encontrando meios de significar sua existência. E, nesse ponto, vale dizer que alguns pesquisadores, ao tratarem da história da escultora, aí localizam uma relação erotômana, apoiando-se no fato de que Camille acreditou ser amada por Rodin, sem que isso houvesse ocorrido. Rosa (2012), com sua experiência clínica em psicanálise, lembra que Camille não corresponde a caso paradigmático de erotomania em sua pureza, se é possível utilizar essa expressão, como foi possível observar em Aimée e seu amor pelo príncipe de Galles, ou no amor de Angélique por seu vizinho. O que os fatos mostram é que Rodin a amou, embora optasse por viver com Rose. Essa decisão não foi sem consequências: ainda que disfarçasse, ficou desolado, teve a saúde, a aparência e a produção abaladas.

A partir de 1905, a decadência de Camille acentuou-se. Tornou-se cada vez mais arisca, reclusa em seu ateliê, produzindo menos e com muita dificuldade financeira. Rodin não é menos afetado pela perda: ele seguia inconsolável com a separação. No fim de sua vida, em momentos de desvario, ele perguntava a Rose onde estava sua mulher e ela lhe respondia que estava bem ali, mas ele continuava a interrogar, dizendo que desejava saber da outra mulher, Camille, aquela que estava em Paris, e temia que ela estivesse precisando de dinheiro (Wahba, 2001). Camille permanecia em seu ateliê descuidado, trazendo gatos para viver ali, muito irritada com Rodin e iniciando a apresentação de um quadro persecutório, alegando que ele estava roubando suas ideias, difamando-a e também espionando-a. Chegou a delirar acerca de um complô que escultores, 
críticos, modelos, práticos, fundidores e admiradores faziam, para plagiá-la, roubá-la, aniquilar sua obra, conforme conta Wahba (2001)

Quando seu pai faleceu, em 1913, Camille foi internada em um hospício, e seu irmão, Paul, a quem era muito ligada, não a amparou e mostrou-se indiferente a seu sofrimento. Não desejava se expor por ocupar uma posição política e também não queria prejudicar sua fama de escritor. Camille permaneceu um ano internada em Paris e depois foi transferida para o asilo de Montdevergues, considerado lugar de despejo de pessoas que não eram bem-vindas por suas próprias famílias. Lá, as internas quase nunca eram visitadas, e, por vezes, adoeciam em razão do frio ou de alimentação inadequada (Wahba, 2001). Ela escrevia cartas para parentes, algumas para a mãe e o irmão, pedindo para que intercedessem por ela, alegando sentimentos permeados por tramas delirantes de perseguição.

Rodin não se manifestou no sentido de impedir a internação de Camille, pois, assim como o irmão, temia expor sua vida e sua carreira, e também não voltou mais a encontrar-se com ela até morrer, em 1917. A mãe de Camille nunca foi visitá-la, ainda que os médicos recomendassem que lhe faria bem estar perto da família, sugerindo um retorno ao lar ou a uma casa de repouso próxima dela, e embora ela manifestasse vontade sair daquele lugar e ficar mais perto de Paris, viver no campo, e se entristecesse por não receber visitas. Em 1943, ela faleceu, no asilo.

Para Drummond (2011), as cartas de Camille mostram uma demanda desesperada endereçada à mãe, nunca obtendo resposta. Nas correspondências endereçadas à mãe, mostrava-se dócil, embora nunca tivesse se dado bem com ela. Algumas vezes, de forma velada, a censurava pelo abandono, outras vezes, deixava bem claro seu descontentamento por viver no asilo. Sempre se queixava de abandono, solidão, de estar presa, privada, do frio intenso e da cama de ferro gelada... E nenhuma resposta chegava.

\section{CONSIDERAÇÕES FINAIS}

Como se pode concluir, o amor não é exclusividade dos neuróticos, que ensinaram a Freud sua possibilidade imaginária e vocação para perturbação do ideal do eu, certa subdução simbólica. Nas psicoses, em que o imaginário cumpre função crucial, ele também acontece: em parcerias que mortificam, as mais comuns, que estabilizam os sujeitos, muito raras, e nas parcerias amorosas com seus delírios. Os psicóticos amam seus delírios

No caso específico do paranoico, é bom recordar, trata-se de sujeito para o qual nem todo simbólico é real. Ele consegue constituir uma imagem corporal 
e a retirada da libido, que chegou a ser investida no mundo, retorna para o eu, em narcisismo absoluto com função de controlar a libido desviada do objeto. Esse sujeito é o intérprete que acaba vendo, a seu redor, sinais que considera referidos a ele, autorreferentes, na certeza de que não há acaso. Assim Camille passou seus últimos anos de vida. E não foi, portanto, sem razão que Freud chamou a paranoia de psicose intelectual, já que se estrutura sob o modo de interpretações delirantes, que, nas formas clássicas, contam com delírio de perseguição, erotomania e delírio de ciúmes.

O paranoico, dessa forma, sempre elege um Outro para o qual se torna objeto especial: na perseguição, o perseguidor; na erotomania, aquele que o ama; no ciúme, aquele que o trai. Ao ler o que se escreveu sobre a vida de Camille, facilmente se pode localizar esses seus pontos em relação ao Outro, com ela na posição de objeto de sua raiva, desprezo, maus-tratos... A parceria amorosa levou ao desencadeamento da psicose, com o delírio apresentando-se sob a necessidade de encontrar novo sentido para o vazio de significação que surgiu, diante da derrocada das coordenadas imaginárias que a sustentavam. $\mathrm{O}$ amor por Rodin, que, em primeiro momento, contribuiu para mantê-la estabilizada, também a devastou, atualizando a devastação vivida com a mãe hostil que a via como uma inimiga. E ali estava ela, na posição de objeto ante o Outro mau.

O delírio é um trabalho desenvolvido pelos psicóticos, de forma lenta ou rápida, com talento maior ou menor. Camille mostrava-se hábil nessa nova arte de ordenar sua vida. E muito precisa na arte de ensinar a devastação que o amor pode causar. 


\section{REFERÊNCIAS}

Aristóteles. (2005). Ética a Nicômaco. São Paulo: Martin Claret.

Drummond, C. (2011). Devastação. Opção Lacaniana, 2(6), 1-14. Recuperado a partir de http://www.opcaolacaniana.com.br/nranterior/numero6/texto5. html

Ebtinger, P. (2006). El amor posible. In J-A. Miller (Org.), El amor en las psicosis. (pp. 55-74). Buenos Aires: Paidós.

Ferrari, I. F. (2009). Acerca do amor e algumas de suas particularidades na psicose. Arquivos Brasileiros de Psicologia, 61(3), 87-96. Recuperado a partir de http://pepsic.bvsalud.org/pdf/arbp/v61n3/v61n3a10.pdf

Ferreira, N. (2004). A teoria do amor. Rio de Janeiro: Jorge Zahar.

Figueiredo, A. C., \& Munõz, N. M. (2015). Um amor morto: considerações acerca de um caso de paranoia. In A. Quinet (Org.), Na mira do Outro. (pp. 143-150). Rio de Janeiro: Contra Capa.

Lacan, J. (1932/2011). Da psicose paranoica em suas relaçôes com a personalidade. Rio de Janeiro: Forense Universitária, 2011. (Publicado originalmente em 1932).

Lacan, J. (1955/1988). O seminário: livro 3: as psicoses. Rio de Janeiro: Zahar, 1988. (Publicado originalmente em 1955).

Lacan, J. (1957/1988). O seminário: livro 5: as formaçôes do inconsciente. Rio de Janeiro: Zahar, 1988. (Publicado originalmente em 1957).

Lacan, J. (1960/2010). O seminário: livro 8: a transferência. Rio de Janeiro: Zahar, 2010. (Publicado originalmente em 1960).

Lacan, J. (1964/2008). O seminário: livro 11: os quatro conceitos fundamentais da psicanálise. Rio de Janeiro: Zahar, 2008. (Publicado originalmente em 1964).

Lacan, J. (1972-1973/2008). O seminário: livro 20: mais, ainda. Rio de Janeiro: Zahar, 2008. (Publicado originalmente em 1972-1973).

Lacan, J. (1976). Conférences et entretiens dans des universités nord-américaines. Scilicet, 6-7, 5-63. 
Miller, J.-A. (2000). A teoria do parceiro. In E. Monteiro, \& V. A. Ribeiro (Orgs.), Os circuitos do desejo na vida e na análise. A. Harari, (Trad.), pp. 153207). Rio de Janeiro: Contra Capa.

Miller, J.-A. (2003). La pareja e el amor. Bueno Aires: Zahar.

Miller, J.-A. (2006). Palabras preliminares. In J. A. Miller. El amor en las psicosis. (pp. 10-12). Buenos Aires: Paidós.

Muñoz, N. M. (2010). Do amor à amizade na psicose: contribuições da psicanálise ao campo da saúde mental. Revista Latino Americana de Psicopatologia Fundamental, 13(1), 87-101. Recuperado a partir de https://doi.org/10.1590/S1415-47142010000100006

Rocha, A. M. L. (2001). Escolha da paixão: um processo de criação e construção do ser pensado à luz da psicanálise. São Paulo: Vetor.

Rosa, J. S. S. (2012). Estrutura, devastação e erotomania: um estudo preliminar. Opção Lacaniana, 3(7), 1-7. Recuperado a partir de http://www.opcaolacaniana.com.br/pdf/numero_7/Estrutura_devastacao_ erotomania.pdf

Wahba, L. L. (2001). Camille Claudel: criação e loucura. Rio de Janeiro: Rosa dos Tempos. 